\title{
Effects of cytochalasin congeners, microtubule-directed agents, and doxorubicin alone or in combination against human ovarian carcinoma cell lines in vitro
}

\author{
Matthew Trendowski, Timothy D. Christen, Christopher Acquafondata and Thomas P. Fondy
}

\begin{abstract}
Background: Although the actin cytoskeleton is vital for carcinogenesis and subsequent pathology, no microfilament-directed agent has been approved for cancer chemotherapy. One of the most studied classes of microfilament-directed agents has been the cytochalasins, mycotoxins known to disrupt the formation of actin polymers. In the present study, we sought to determine the effects of cytochalasin congeners toward human drug sensitive and multidrug resistant cell lines.
\end{abstract}

Methods: SKOV3 human ovarian carcinoma and several multidrug resistant derivatives were tested for sensitivity against a panel of nine cytochalasin congeners, as well as three clinically approved chemotherapeutic agents (doxorubicin, paclitaxel, and vinblastine). In addition, verapamil, a calcium ion channel blocker known to reverse P-glycoprotein (P-gp) mediated drug resistance, was used in combination with multiple cytochalasin congeners to determine whether drug sensitivity could be increased.

Results: While multidrug resistant SKVLB1 had increased drug tolerance (was more resistant) to most cytochalasin congeners in comparison to drug sensitive SKOV3, the level of resistance was 10 to 1000-fold less for the cytochalasins than for any of the clinically approved agents. While cytochalasins did not appear to alter the expression of ATP binding cassette $(A B C)$ transporters, several cytochalasins appeared to inhibit the activity of ABC transporter-mediated efflux of rhodamine 123 (Rh123), suggesting that these congeners do have affinity for drug efflux pumps. Cytochalasins also appeared to significantly decrease the F/G-actin ratio in both drug sensitive and drug resistant cells, indicative of marked microfilament inhibition. The cytotoxicity of most cytochalasin congeners could be increased with the addition of verapamil, and the drug sensitivity of resistant SKVLB1 to the clinically approved antineoplastic agents could be increased with the addition of cytochalasins. As assessed by isobolographic analysis and Chou-Talalay statistics, cytochalasin B and 21,22-dihydrocytochalasin B (DiHCB) demonstrated notable synergy with doxorubicin and paclitaxel, warranting further investigation in a tumor-bearing mammalian model.

Conclusion: Cytochalasins appear to inhibit the activity of P-gp and potentially other ABC transporters, and may have novel activity against multidrug resistant neoplastic cells that overexpress drug efflux proteins.

\footnotetext{
* Correspondence: mrtrendo@syr.edu

Department of Biology, Syracuse University, 107 College Place, Syracuse, NY 13244, USA
} 


\section{Background}

Cytochalasins are mycotoxins known to disrupt the formation of filamentous (F)-actin, thereby preventing the formation of functional microfilaments. These congeners are characterized by a highly substituted perhydroisoindolone structure that is typically attached to a macrocyclic ring [1]. More than 60 different cytochalasins from several species of fungi have been classified into various subgroups based on the size of the macrocyclic ring and the substituent of the perhydroisoindolyl-1-one residue at the C-3 position [2]; structures of representative cytochalasins are shown in Fig. 1. While most of our previous work has focused on cytochalasin B, there are many other congeners with similar activity toward microfilaments. As microfilament-disrupting agents, cytochalasins alter cell motility, adherence, secretion, drug efflux, deformability, morphology, and size, among many other cell properties critical to neoplastic cell pathology $[1,2]$. In addition, two of the congeners (cytochalasins B and D) have shown partial specificity against neoplastic cells [3-10], consistent with the substantial differences known to exist between the microfilament biochemistry of neoplastic and normal cells $[11,12]$. These differences in microfilament structure may be related to key neoplastic characteristics, including altered adherence, anchorage independent growth, invasiveness, and altered plasma membrane cytoskeletal interactions involving expression of oncoproteins [12, 13].
Previously, we have demonstrated that cytochalasin B and its reduced congener 21,22-dihydrocytochalasin B (DiHCB) are able to sensitize multidrug resistant P388/ ADR murine leukemia cells to doxorubicin, with both congeners showing considerable drug synergy with the nucleic acid-directed agent [14]. In addition, prior research has indicated that cytochalasin B efflux is less affected by overexpression of ATP binding cassette $(\mathrm{ABC})$ transporters than other cytotoxic drug classes (vinca alkaloids and anthracyclines) [15] that often exhibit drug resistance in the clinical setting. Based on these observations, it appears that cytochalasin B and potentially other cytochalasin congeners might be active against multidrug resistant neoplastic cells and might also be able to overcome resistance to other cytotoxic agents currently used in the clinical setting. Therefore, this study seeks to determine the effects of cytochalasin congeners toward drug sensitive and multidrug resistant human cancer cell lines.

SKOV3 is a human ovarian carcinoma cell line frequently used in vitro and also in vivo as a xenograft in immunosuppressed mice. SKOV3 cells have slight, but noticeable resistance to tumor necrosis factor, as well as to cisplatin and doxorubicin [16, 17]. The inherent drug resistance of SKOV3 cells can be dramatically elevated through progressively increasing exposure to either vinblastine or vincristine [18]. One of the most notable multidrug resistant cell lines, SKVLB1, is 2,000-fold more resistant to vinblastine,<smiles>CCCCC1CC(C)[C@H](C)C2[C@@H](C)NC(CCCC)[C@]12C</smiles>

Macrocycle Skeleton of Cytochalasins

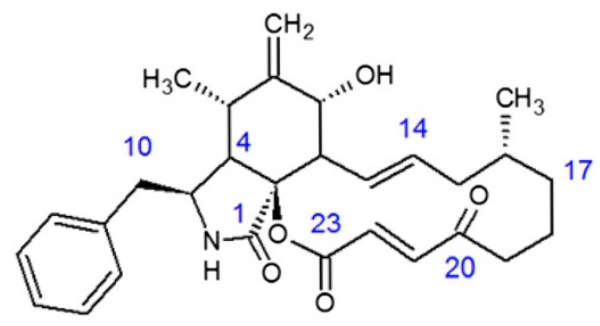

Cytochalasin A



\section{1, 22-Dihydrocytochalasin B $\gamma$-L}

Fig. 1 Molecular structure of the cytochalasin macrocycle and several congeners. The macrocycle skeleton of cytochalasins is provided to indicate the numbering system used for these congeners. In addition, the structure of 21,22-dihydrocytochalasin B is shown to indicate the differences in structure it has with the $\gamma$-lactone derivative. The a, $\beta$-unsaturated ketones of cytochalasin A runs from C-20 to C-23 
10,000-fold more resistant to vincristine, 260-fold more resistant to doxorubicin, and 510-fold more resistant to the non-clinically approved colchicine when compared to the parental cell line [18]. Further, this increase in drug resistance is mirrored by increasing overexpression of $\mathrm{P}$ glycoprotein (P-gp), a known $\mathrm{ABC}$ transporter $[19,20]$. Since cytochalasin B efflux is notably resistant to P-gp overexpression, drug sensitive and drug resistant SK human ovarian carcinoma cell lines are ideal models to examine cytochalasin sensitivity in multidrug resistant cancers. These cell lines can also reveal potential drug synergism when cytochalasin congeners are combined with chemotherapeutic agents, or with calcium ion channel blockers known to inhibit P-gp drug efflux [20-24].

\section{Methods}

\section{Preparation of human ovarian carcinoma cell lines}

SK human ovarian carcinoma cell lines with varying levels of drug resistance were provided courtesy of Dr. Victor Ling (University of British Columbia, Canada). The level of drug resistance of the cell lines from lowest to highest is as follows: SKOV3 (parental cell line), SKVCR0.015, SKVCR0.1, and SKVLB1 (see Reference [18] for details on how drug resistance is acquired). All cell lines were seeded at $4 \times 10^{4}$ cells $/ \mathrm{cm}^{2}$ in $25 \mathrm{~cm}^{2}$ culture flasks, and suspended in $9 \mathrm{ml}$ of RPMI 1640 complete medium containing $10 \%$ newborn calf serum (GIBCO, Grand Island, NY, USA), $0.4 \mathrm{units} / \mathrm{ml}$ penicillin, $0.4 \mu \mathrm{l} / \mathrm{ml}$ streptomycin, and $250 \mu \mathrm{g} / \mathrm{ml}$ fungizone. Flasks were incubated in $5 \% \mathrm{CO}_{2}$ at $37{ }^{\circ} \mathrm{C}$. During subculture, cells were trypsinized with $0.05 \%$ trypsin-EDTA solution 1X (Sigma-Aldrich Corp., St. Louis, MO, USA) for $5 \mathrm{~min}$ at $37^{\circ} \mathrm{C}$, dislodged by a sharp knocking of the flasks during that period, washed, diluted to $10 \mathrm{ml}$ with fresh complete medium, and $1 \times 10^{6}$ cells were seeded into $25 \mathrm{~cm}^{2}$ culture flasks $\left(4 \times 10^{4}\right.$ cells $\left./ \mathrm{cm}^{2}\right)$.

\section{Cytochalasin B preparation}

Cytochalasin B was prepared from mold mattes of Drechslera dematioidea (ATCC ${ }^{\bullet}$ 24346) as previously described [13, 14, 25], and purified by preparative thin layer chromatography to greater than $99 \%$ homogeneity after recrystallization from chloroform. Cytochalasin B and other cytochalasins prepared in our laboratory were characterized with ${ }^{1} \mathrm{H}$ NMR spectroscopy (spectra not shown), and were compared to commercially acquired samples (Sigma-Aldrich Corp.) to ensure that the isolated products were of a suitable grade.

\section{1, 22-Dihydrocytochalasin B Preparation}

DiHCB was prepared by sodium borohydride reduction of cytochalasin $\mathrm{B}$ in methanol at $25^{\circ} \mathrm{C}$ as previously described $[14,26]$. The product was recovered as a chloroformsoluble fraction and crystallized from benzene:hexane. DiHCB was compared to a commercially purchased sample of DiHCB (Sigma-Aldrich Corp.) and cytochalasin B (Sigma-Aldrich Corp.) using reverse phase thin layer chromatography.

\section{Cytochalasin D preparation}

Cytochalasin D was prepared from mold mattes of Zygosporium masonii (ATCC ${ }^{\bullet}$ MYA3308) as previously described [14,26], and purified by preparative thin layer chromatography to greater than $99 \%$ homogeneity after recrystallization from chloroform.

\section{Cytochalasin C preparation}

Cytochalasin $\mathrm{C}$ was prepared through an isomerization reaction of cytochalasin D using a Pd/charcoal catalyst at $25{ }^{\circ} \mathrm{C}$ as previously described [26]. After filtration of the charcoal catalyst, cytochalasin $\mathrm{C}$ was isolated from any remaining cytochalasin $\mathrm{D}$ in the reaction product using $\mathrm{C}$ 18 reverse phase thin layer chromatography plates with methanol:water, $75: 25 \mathrm{v} / v$ as mobile phase, followed by fluorescence quenching. A small amount of commercial cytochalasin C (Sigma-Aldrich Corp.) was characterized by reverse phase thin layer chromatography and recrystallized from acetone:hexane for comparison with the purified product.

\section{Preparation of other cytochalasin congeners}

All other cytochalasin congeners (cytochalasins A, E, H, $\mathrm{J}$, and $\mathrm{DiHCB} \gamma-\mathrm{L}$ ), were acquired commercially (SigmaAldrich Corp.). All cytochalasins used in the study were solubilized by dissolving $1.0 \mathrm{mg}$ cytochalasin in $100 \mu \mathrm{l}$ $\mathrm{EtOH}$ in conical $1.5 \mathrm{ml}$ plastic centrifuge tubes. Once the entire compound went into solution, $100 \mu \mathrm{l}$ of the $10 \mathrm{mg} / \mathrm{ml}$ cytochalasin/EtOH solution was diluted into $4.9 \mathrm{ml}$ medium to give a $400 \mu \mathrm{M}$ stock solution with $2 \%$ $\mathrm{EtOH}$.

\section{Preparation of clinically approved chemotherapeutic agents}

Doxorubicin, paclitaxel, and vinblastine were acquired commercially (Sigma-Aldrich Corp.). Doxorubicin was solubilized in isotonic saline, paclitaxel in 1:1 $100 \%$ EtOH: Kolliphor EL, and vinblastine in sterilized water.

\section{Plate assay procedures}

SK human ovarian carcinoma cells were tested for drug sensitivity using 24-well assay plates (Corning Life Sciences, Corning, NY, USA). Each well contained $\sim 1000$ cells in $1 \mathrm{ml}$ medium. Agents were then dissolved in the wells at varying concentrations for 23 wells, while the last well remained untreated. The plates were incubated at $37{ }^{\circ} \mathrm{C}$ for the length of drug exposure, and then stained with methylene blue. This method was then used to assess varying inhibitory concentrations of each agent alone or in combination with another agent as described in [18]. The 
efficacy of the method was also confirmed with a XTT Cell Proliferation Assay Kit (ATCC ${ }^{\ominus} 30-1011$ K).100 $\mu \mathrm{l}$ of cells were seeded per well into a flat-bottom 96-well microtiter plate in triplicate for each cell dilution. The plate was incubated for $24 \mathrm{~h}$ prior to addition of XTT solution. Cells were then incubated for an additional $2 \mathrm{~h}$ before the wavelength was read.

\section{Examining the effects of cytochalasins on microfilaments in neoplastic cells}

Cytochalasins were assessed for their ability to inhibit the formation of F-actin by examining the ratio of F-actin to monomeric globular (G)-actin found within the SK human ovarian cancer cell lines prior to and after treatment. The F-actin to G-actin ratio was determined with the G-Actin/ F-Actin In Vivo Assay Biochem Kit (Cytoskeleton Inc., Denver, CO, USA). After being treated, cells were lysed with LAS2 buffer (1 ml lysis and F-actin stabilization buffer, $10 \mu \mathrm{l}$ of the $100 \mathrm{mM}$ ATP stock solution, and $10 \mu \mathrm{l}$ of the $100 \times$ protease inhibitor cocktail stock solution) on ice for $10 \mathrm{~min}$. Cells were collected and the cell extracts were centrifuged at $4{ }^{\circ} \mathrm{C}$ for $75 \mathrm{~min}$ at $16,000 \mathrm{~g}$ to separate the Factin and G-actin pools. The supernatants of the extracts were collected and designated as the G-actin pool. The pellets were resuspended in ice-cold actin depolymerization buffer and designated as the F-actin pool. Equal amounts of both the supernatant (G-actin) and the resuspended pellet (F-actin) were subjected to Western blot analysis with the use of an anti- $\beta$-actin antibody.

\section{Assessing the inhibitory activity cytochalasins have toward ATP binding cassette transporters}

To determine whether cytochalasins exert antineoplastic activity via inhibition of $\mathrm{P}$-gp and other $\mathrm{ABC}$ transporters, reverse transcription polymerase chain reaction (RT-PCR) was used to quantify the RNA levels of three $A B C$ transporters; P-gp (ABCB1), Multidrug resistance-associated protein 1 (MRP1; $A B C C 1)$ and multidrug resistanceassociated protein 2 (MRP2; ABCC2). Total RNA was extracted from cells according to instructions provided in the RNeasy Mini kit (Qiagen Inc., Valencia, CA, USA). Successfully extracted RNA was then dissolved in diethylpyrocarbonate/water. Absorption values were read at $260 \mathrm{~nm}$ and $280 \mathrm{~nm}$ using a UV spectrophotometer. Acquired RNA was converted into cDNA according to the instructions provided in the RT-PCR kit (Life Technologies, Grand Island, NY, USA), and primers used for RT-PCR are shown in Table 1. The reaction was carried out under the following conditions: denaturation at $95{ }^{\circ} \mathrm{C}$ for $5 \mathrm{~min}$ with an additional $15 \mathrm{~s}$ at $94{ }^{\circ} \mathrm{C}$, and a $30 \mathrm{~s}$ annealing at $60{ }^{\circ} \mathrm{C}$. Targets genes were directly quantified to the reference gene $\beta$-actin, since cytochalasins do not significantly affect the RNA expression levels of actin [1].
In addition to examining the effects of cytochalasins on the RNA expression of $\mathrm{ABC}$ transporters in human ovarian carcinoma cells, direct inhibitory activity toward drug efflux pumps was assessed with rhodamine 123 (Rh123; 6-amino9-(2- methoxycarbonylphenyl) xanthen-3-ylidene]azanium chloride). Cells were initially plated at $2 \times 10^{5} \mathrm{cells} / \mathrm{cm}^{2}$ in 24-well plates and allowed to reach $80 \%$ confluence. To assess the ability of cytochalasins to potentiate Rh123 accumulation, cells were incubated with $5 \mu \mathrm{M}$ Rh123 in the presence and in the absence of cytochalasins or the known P-gp inhibitor verapamil for varying lengths of time. At each time point, cells were collected, washed, resuspended in ice-cold phosphate-buffered saline and kept on ice before fluorescence intensity was measured with flow cytometry. Cells were also assessed for their ability to efflux accumulated Rh123 in the presence of cytochalasins or verapamil by initially incubating the cells with $5 \mu \mathrm{M}$ Rh123 for $30 \mathrm{~min}$ and then washing the cells twice with ice-cold PBS before being resuspended in fresh Rh123-free medium with and without agents. Cells were collected at various time points and were then washed and resuspended in ice-cold PBS before being analyzed by flow cytometry.

\section{Determining the extent of drug synergy between cytochalasins, doxorubicin, and paclitaxel}

To assess whether cytochalasin B or DiHCB synergizes with doxorubicin or paclitaxel against SK human ovarian carcinomas in vitro, cells were treated alone, or in combination for 48 or $96 \mathrm{~h}$. $\mathrm{IC}_{50}$ values were assessed by both the methylene blue and XTT assays. In addition, the Chou-Talalay method for assessing drug synergism was implemented to determine the combination index (CI), dose reduction index (DRI), and fraction affected (Fa). As indicated in [27], synergism was assessed with the following values: $\mathrm{CI}<1$ (synergy) $\mathrm{CI}=1$ (additive) $\mathrm{CI}>1$ (antagonism). In addition, DRI $>1$ is representative of favorable dose reduction, while DRI $<1$ is representative of unfavorable dose reduction [27].

\section{Results}

Comparison of cytochalasin congeners and other antineoplastic agents against SK human ovarian carcinoma cell lines

There were notable differences in cytotoxicity between cytochalasin congeners and other antineoplastic agents against the human ovarian carcinoma cell lines. Table 2 shows the comparative $\mathrm{IC}_{90}$ values and resistance indices for nine cytochalasin congeners and for doxorubicin, paclitaxel, and vinblastine. While doxorubicin, paclitaxel, and vinblastine all had comparatively low $\mathrm{IC}_{90}$ values against the parent SKOV3 cell line after a $96 \mathrm{~h}$ exposure indicative of relatively high efficacy, $(11 \mathrm{nM}, 2.8$ $\mathrm{nM}$, and $1.9 \mathrm{nM}$, respectively), these agents had relatively higher $\mathrm{IC}_{90}$ values against the intermediately drug 
Table 1 Primer sequences used for reverse transcription polymerase chain reaction to quantify RNA expression of ATP binding cassette transporters in SK human ovarian carcinoma cell lines

\begin{tabular}{llll}
\hline Gene and NCBI ID & Forward primer & Reverse primer & $T_{A}\left(^{\circ} \mathrm{C}\right)$ \\
\hline ABCB1 (5243) & 5'-GCC CTT GGA ATT ATT TCT TT-3' & 5'-TGG GTG AAG GAA AAT GTA AT-3' \\
ABCC1 (4363) & 5'-ATG TCA CGT GGA ATA CCA GC-3' & 5'-GAA GAC TGA ACT CCC TTC CT-3' \\
ABCC2 (1244) & 5'-GGA ACA ATT GTA GAG AAA GGA TC-3' & 5'-CAC AAA CGC AAG GAT GAT GAA GAA-3' \\
\hline
\end{tabular}

resistant SKVCR0.015 and SKVCR0.1 lines (125 nM and $125 \mathrm{nM}$ for doxorubicin, $8 \mathrm{nM}$ and $4 \mathrm{nM}$ for paclitaxel, and $10 \mathrm{nM}$ and $20 \mathrm{nM}$ for vinblastine, respectively), indicative of drug resistance. The SKVLB1 cell line showed even higher resistance to these three agents exhibiting much higher $\mathrm{IC}_{90}$ values $(2900 \mathrm{nM}, 3900 \mathrm{nM}$, and $3100 \mathrm{nM}$, respectively; Table 2). The profound differences in cytotoxicities of these agents against the drug sensitive parental SKOV3 line compared to the multidrug resistant SKVLB1 line produced very high resistance indices (RI values). These RI values ranged from 264 for doxorubicin to 1,400 and 1,600 for paclitaxel and vinblastine for SKVLB1 in comparison with SKOV3.

By contrast, cytochalasins did not show this marked increase in resistance against the multidrug resistant SKVLB1 line (Table 2). In fact, cytochalasin A produced a lower $\mathrm{IC}_{90}$ value against SKVLB1 $(750 \mathrm{nM})$ than against SKOV3 $(1,000 \mathrm{nM})$. Interestingly, the most cytotoxic congeners with $\mathrm{IC}_{90}$ values of $330 \mathrm{nM}$ or less against drug sensitive SKOV3 (cytochalasins $\mathrm{C}, \mathrm{D}, \mathrm{E}$, and $\mathrm{H}$ ) had higher RIs against SKVLB1 than did cytochalasins A, B, J, DiHCB, or DiHCBY-L; those with higher initial $\mathrm{IC}_{90}$ values (lower initial cytotoxicity against SKOV3). Nevertheless, the congener with the highest RI against SKVLB1, cytochalasin C (RI = 100 against SKVLB1), still had a considerably lower
RI than the clinically approved chemotherapeutic agents (doxorubicin $\mathrm{RI}=264$, paclitaxel $\mathrm{RI}=1,400$, and vinblastine $\mathrm{RI}=1,600$ ). The differences in cytotoxicity expressed as $\mathrm{IC}_{90}$ values along with the respective RI values as shown in Table 2 are further highlighted in Fig. 2, which uses a logarithmic scale to compare the cytotoxicities of agents against SKOV3 and SKVLB1.

\section{Effects of a calcium ion channel blocker on cytochalasin-mediated cytotoxicity}

As shown in Table 3, the calcium ion channel blocker verapamil increased the drug sensitivity of parental SKOV3 to cytochalasins A, B, and DiHCB by 1.2 to 2 -fold. Sensitivity to cytochalasins $\mathrm{C}$ and $\mathrm{D}$ was not enhanced. With respect to the highly drug-resistant SKVLB1 line, verapamil did not notably increase cytochalasin A cytotoxicity. This presumably reflects the fact that cytochalasin A has slightly enhanced cytotoxicity for SKVLB1 than it does for SKOV3.

Sensitivity of SKVLB1 to cytochalasin B or DiHCB was increased by 1.5 fold. Very strikingly, the sensitivity of SKVLB1 to cytochalasins C and D was markedly increased by 32 - and 64-fold respectively. The SK lines with intermediate resistance to SKVLB1 (SKVCR0.015 and SKVCR0.1) showed a 1.5 to 2-fold increase in sensitivity to cytochalasins $\mathrm{A}, \mathrm{B}$, and $\mathrm{DiHCB}$ when

Table 2 Effects of clinically approved natural product antineoplastic agents and of cytochalasin congeners on drug-sensitive and multidrug-resistant human ovarian carcinoma lines

\begin{tabular}{|c|c|c|c|c|c|c|c|}
\hline \multirow{2}{*}{$\begin{array}{l}\text { Cell line } \\
\text { IC concentrations (nM) at } 96 \mathrm{~h} \\
\end{array}$} & \multirow{2}{*}{$\begin{array}{l}\mathrm{SKOV}^{\mathrm{a}} \\
\mathrm{IC}_{90}\end{array}$} & \multicolumn{2}{|c|}{ SKVCR0.015 } & \multicolumn{2}{|c|}{ SKVCR0.1 } & \multicolumn{2}{|c|}{ SKVLB1 } \\
\hline & & $\mathrm{IC}_{90}$ & $\mathrm{RI}$ & $\mathrm{IC}_{90}$ & $\mathrm{RI}$ & $\mathrm{I}_{90}$ & $\mathrm{RI}$ \\
\hline Doxorubicin & 11 & 125 & 11 & 125 & 11 & 2900 & 264 \\
\hline Paclitaxel & 2.8 & 8 & 3 & 4 & 1.4 & 3900 & 1400 \\
\hline Vinblastine & 1.9 & 10 & 5 & 20 & 10 & 3100 & 1600 \\
\hline Cytochalasin A & 1000 & 1000 & 1 & 500 & 0.5 & 750 & 0.75 \\
\hline Cytochalasin B & 2250 & 1500 & 0.67 & 1250 & 0.56 & 3000 & 1.33 \\
\hline 21, 22-Dihydrocytochalasin B & 3000 & 2400 & 0.8 & 1600 & 0.53 & 5000 & 2.5 \\
\hline 21, 22-Dihydrocytochalasin B $\gamma-L$ & 40000 & 30000 & 0.75 & 30000 & 0.75 & 40000 & 1 \\
\hline Cytochalasin C & 330 & 250 & 0.76 & 125 & 0.38 & 8000 & 24 \\
\hline Cytochalasin D & 80 & 80 & 1 & 320 & 4 & 8000 & 100 \\
\hline Cytochalasin E & 200 & ND & & ND & & 1600 & 8 \\
\hline Cytochalasin $\mathrm{H}$ & 100 & ND & & ND & & 1600 & 16 \\
\hline Cytochalasin J & 800 & ND & & ND & & 3200 & 4 \\
\hline
\end{tabular}

$N D$ not determined, $R /$ resistance index compared to parental SKOV3 line

${ }^{\mathrm{a}} \mathrm{RI}=1$ for all agents for SKOV3 line 




Fig. 2 Comparison of clinically approved chemotherapeutic agents and cytochalasin congeners against SKOV3 drug sensitive and SKVLB1 multidrug resistant human ovarian carcinomas. Abbreviations used are as follows: ADR (Adriamycin; doxorubicin), Tax (paclitaxel), VBL (vinblastine), CA (cytochalasin A), CB (cytochalasin B), DiHCB (21,22-dihydrocytochalasin B), CC (cytochalasin C), CD (cytochalasin D), CE (cytochalasin E), CH (cytochalasin H), and $\mathrm{CJ}$ (cytochalasin J). The concentration of each agent in $\mathrm{nM}$ needed to produce an $\mathrm{I}_{90}$ value at $96 \mathrm{~h}$ for either cell line is represented on a logarithmic scale. The resistance index (RI) of each compound against SKVLB1 is indicated in bold underneath the abbreviations

Table 3 Effects of verapamil on the sensitivity of human ovarian carcinoma cell lines to cytochalasin congeners

\begin{tabular}{|c|c|c|c|c|c|c|c|c|}
\hline \multirow{2}{*}{$\begin{array}{l}\text { Cell line } \\
\text { IC concentrations }(\mu \mathrm{M}) \text { at } 96 \mathrm{~h}\end{array}$} & \multicolumn{2}{|c|}{ SKOV3 } & \multicolumn{2}{|c|}{ SKVCR0.015 } & \multicolumn{2}{|c|}{ SKVCR0.1 } & \multicolumn{2}{|c|}{ SKVLB1 } \\
\hline & $\mathrm{IC}_{90}$ & FS & $\mathrm{I}_{90}$ & FS & $\mathrm{IC}_{90}$ & FS & $\mathrm{IC}_{90}$ & FS \\
\hline \multicolumn{9}{|l|}{ Cytochalasin A } \\
\hline Alone & 0.8 & - & 0.8 & - & 0.2 & - & 0.75 & - \\
\hline 15 MM Verapamil & 0.4 & 2 & 0.4 & 2 & 0.1 & 2 & ND & \\
\hline 30 M Verapamil & 0.4 & 2 & 0.4 & 2 & 0.1 & 2 & 0.75 & - \\
\hline \multicolumn{9}{|l|}{ Cytochalasin B } \\
\hline Alone & 2.3 & - & 1.5 & - & 1.1 & - & 3 & - \\
\hline 15 MM Verapamil & 1.2 & 1.9 & 1 & 1.5 & 0.55 & 2 & ND & \\
\hline $30 \mu \mathrm{M}$ Verapamil & 1.1 & 2 & 0.75 & 2 & 0.55 & 2 & 2 & 1.5 \\
\hline \multicolumn{9}{|l|}{ 21, 22-Dihydrocytochalasin B } \\
\hline Alone & 3 & - & 2.4 & - & 1.6 & - & 5 & - \\
\hline 15 M Verapamil & 2.5 & 1.2 & 1.5 & 1.6 & 1.0 & 1.6 & ND & \\
\hline 30 M Verapamil & 2 & 1.5 & 1.3 & 1.8 & 0.8 & 2 & 3.2 & 1.57 \\
\hline \multicolumn{9}{|l|}{ Cytochalasin C } \\
\hline Alone & 0.25 & - & 0.25 & - & 0.25 & - & 8 & \\
\hline 15 M Verapamil & ND & & ND & & ND & & ND & \\
\hline 30 M Verapamil & 0.25 & 1 & 0.25 & 1 & 0.125 & 2 & 0.25 & 32 \\
\hline \multicolumn{9}{|l|}{ Cytochalasin D } \\
\hline Alone & 0.08 & - & 0.08 & - & 0.1 & - & 8 & \\
\hline 15 M Verapamil & 0.08 & 1 & 0.06 & 1.5 & 0.1 & 1 & ND & \\
\hline 30 M Verapamil & 0.08 & 1 & 0.04 & 2 & 0.075 & 1.5 & 0.13 & 64 \\
\hline
\end{tabular}


administered in combination with $15 \mu \mathrm{M}$ verapamil, and cytochalasin D had a similar increase in sensitivity with $30 \mu \mathrm{M}$ verapamil. In addition, verapamil increased the sensitivity of SKVCR0.1 to cytochalasin C by 2 -fold, but did not affect cytochalasin $C$ with respect to SKVCR0.015. The effects of $30 \mu \mathrm{M}$ verapamil on SK human ovarian carcinoma sensitivity to cytochalasins B, C, D and DiHCB are further highlighted in Fig. 3a. Verapamil enhanced the cytotoxicities of cytochalasin B and DiHCB in all four cell lines tested (black and grey bars), and it enhanced the cytotoxicities of cytochalasins $\mathrm{C}$ and $\mathrm{D}$ against SKVCR0.1 by 1.5 to 2 -fold (red and blue bars). The dramatic increases in cytotoxicities of 32- to 64-fold noted above for cytochalasins $C$ and D against the highly drug resistant SKVLB1 line when treated in combination with $30 \mu \mathrm{M}$ verapamil are clearly apparent in Fig. 3a.

This increase in cytotoxicity potentiated by $30 \mu \mathrm{M}$ verapamil in a $96 \mathrm{~h}$ exposure is exhibited at multiple concentrations of cytochalasin A against SKVCR0.015 (Fig. 3b), as well as with the less potent cytochalasin $B$ against the same cell line (Fig. 3c). After continuous exposure for $96 \mathrm{~h}, 30 \mu \mathrm{M}$ verapamil produces a 2.5 -fold increase in cytotoxicity of cytochalasin A at $0.5 \mu \mathrm{M}$, and a 2.8 -fold increase in cytotoxicity of cytochalasin B at $0.25 \mu \mathrm{M}$. The potential increase in cytotoxicity facilitated by verapamil is further highlighted in dose response growth curves of SKVCR0.015 cells after being treated alone with cytochalasins $\mathrm{A}$ or $\mathrm{B}$, or concomitantly with $30 \mu \mathrm{M}$ verapamil for

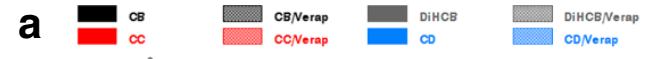

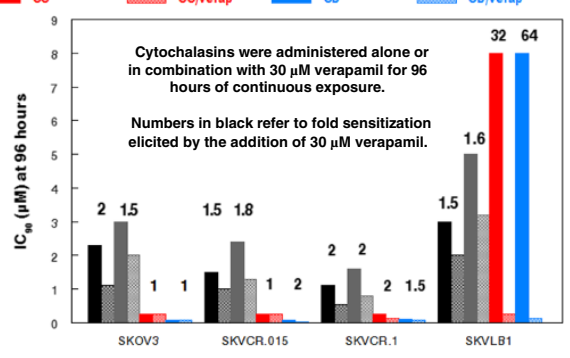

b $\rightarrow C A \quad-A-$ Caveras

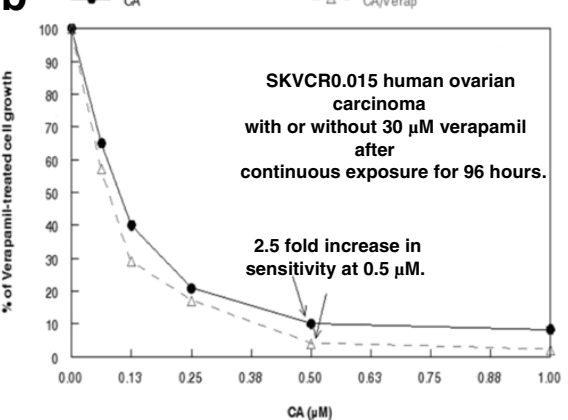

C $\rightarrow \mathrm{CB} \quad-\triangle-\mathrm{CBN}_{\mathrm{N}} \mathrm{Crap}$


Fig. 3 Effects of verapamil and cytochalasins on SK human ovarian carcinoma cell lines. a Effects of verapamil on potentiating SK human ovarian carcinoma sensitivity to cytochalasins B, C, D, and 21,22-dihydrocytochalasin B. Cell lines are arranged in order of increasing drug resistance from left to right. The $\mathrm{IC}_{90}$ concentrations are given in $\mu \mathrm{M}$. Numbers in black refer to fold sensitization elicited by the addition of $30 \mu \mathrm{M}$ verapamil. b Effects of cytochalasin A-alone or in combination with $30 \mu \mathrm{M}$ verapamil against SKVCR0.015 cells. The values are taken as a percentage of $30 \mu \mathrm{M}$ verapamil-treated cells. c Effects of cytochalasin B-alone or in combination with $30 \mu \mathrm{M}$ verapamil against SKVCR0.015 cells. The values are taken as a percentage of $30 \mu \mathrm{M}$ verapamil-treated cells. $\mathbf{d}$ Dose response of cytochalasin A-alone or in combination with $30 \mu \mathrm{M}$ verapamil on the growth of SKVCR0.015 cells. e Dose response of cytochalasin B-alone or in combination with $30 \mu \mathrm{M}$ verapamil on the growth of SKVCR0.015 cells. For panels $\mathbf{d}$ and $\mathbf{e}$, agents were administered for either 48 or $96 \mathrm{~h}$, as indicated in the graphs 
48 or $96 \mathrm{~h}$. While the addition of verapamil does not considerably increase the percent growth inhibition at most time points for cytochalasin A (Fig. 3d), the calcium ion channel blocker does potentiate cytochalasin B mediated growth inhibition, particularly at lower concentrations (Fig. 3e).

\section{Effects of cytochalasins and verapamil on the F/G-actin ratio found in SK human ovarian carcinoma cells}

As expected, cytochalasins demonstrated varying levels of microfilament inhibition against the parental SKOV3 cells, with the more potent agents potentiating lower F/G-actin ratios (Fig. 4). In agreement with their $\mathrm{IC}_{90}$ values against SKOV3, cytochalasin D elicited the lowest F/G actin ratio after $24 \mathrm{~h}$ (8.2), while DiHCB $\gamma$-L elicited the highest (20.9). Interestingly, it appeared that $30 \mu \mathrm{M}$ verapamil had a small, but notable effect on the F/G-actin ratio of SKOV3 cells. The efficacy of various cytochalasin congeners to inhibit actin polymerization was notably different in multidrug resistant SKVLB1. Although the cell line had a smaller, but notable baseline F/G-actin ratio than its parental counterpart (27.5 to 31), SKVLB1 was less sensitive to cytochalasin D inhibition (15.9), but much more sensitive to cytochalasin A (SKOV3: 12.5; SKVLB1: 9.8) and DiHCB $\gamma$-L (17.8), as was indicated by the four day $\mathrm{IC}_{90}$ concentrations. The $\mathrm{F} /$ G-actin ratio potentiated by cytochalasin B/verapamil was lower than cytochalasin B-alone for both SKOV3 (13.4 to 14.3) and SKVLB1 (11.9 to 13.5). The notable decrease in the F/G actin ratio elicited by the concomitant administration of cytochalasin B/verapamil follows the same pattern observed in the cytotoxicity assays of Fig. 3, suggesting verapamil may have a slight, but notable influence on cytochalasin B-mediated cytotoxicity.
Assessment of ATP binding cassette transporter overexpression in SK human ovarian carcinomas and the inhibitory effects of cytochalasins and verapamil

RT-PCR quantification of $A B C$ transporters revealed that P-gp was substantially overexpressed in the drug resistant derivatives of SKOV3, with expression mirroring the level of drug resistance associated with each cell line (Fig. 5a). The overexpression of P-gp in SKVLB1 in comparison to parental SKOV3 is dramatic as Fig. 5a required the use of a logarithmic scale to quantify all expression levels. This pattern was also observed with MRP2, albeit at lower expression levels, while MRP1 increased only minimally between the four cell lines. RT-PCR also revealed that neither $0.3 \mu \mathrm{M}$ cytochalasin A or B influenced the RNA levels of $\mathrm{ABC}$ transporters (Fig. 5a). In fact, only $15 \mu \mathrm{M}$ verapamil influenced RNA expression, with a slight, but noticeable decrease in P-gp levels against all four neoplastic cell lines.

Nevertheless, cytochalasins A and B appeared to have notable inhibitory activity against $\mathrm{ABC}$ transporters, as assessed by Rh123 accumulation and efflux analysis (Fig. 5b and c). SKVLB1 cells treated with $0.3 \mu \mathrm{M}$ cytochalasin A or B readily accumulated Rh123, becoming saturated by the dye at $60 \mathrm{~min}$ (Fig. $5 \mathrm{~b}$ ). This activity was also seen with $15 \mu \mathrm{M}$ verapamil, but not $0.3 \mu \mathrm{M}$ cytochalasin $\mathrm{C}$, which had only a slight influence on accumulation levels. All treatment groups for SKOV3 became saturated by Rh123, indicative of its low expression of P-gp and other efflux pumps. The activity of cytochalasins A and B, as well as verapamil against $A B C$ transporter-mediated efflux of Rh123 was confirmed by experiments in which cells were incubated with the dye prior to being placed in fresh medium (Fig. 5c). Untreated and $0.3 \mu \mathrm{M}$ cytochalasin C treated SKVLB1 cells effluxed Rh123 at a consistent

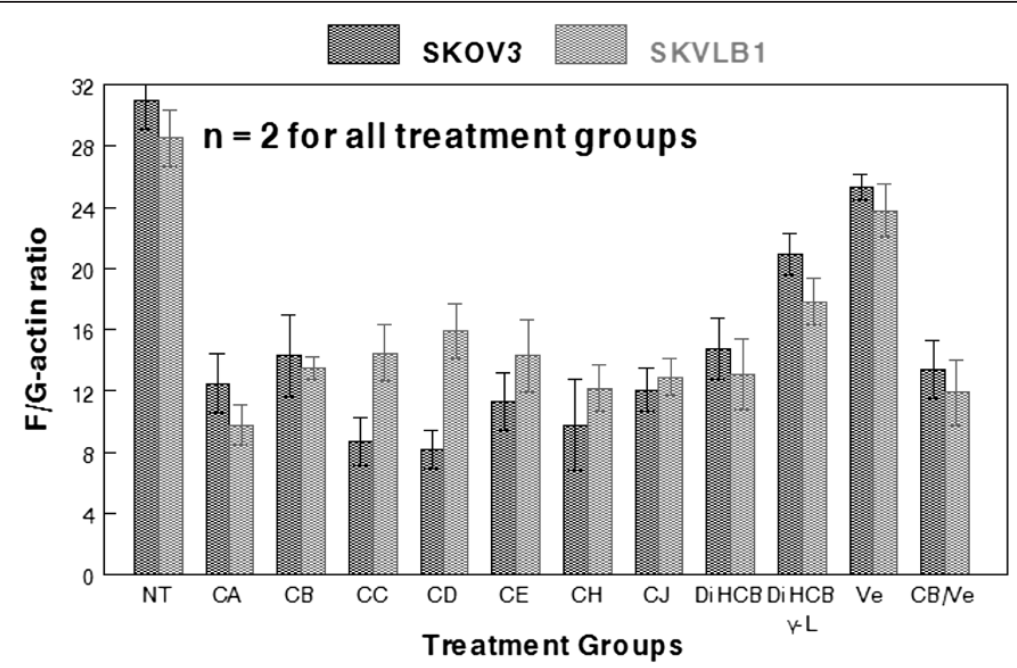

Fig. 4 Effects of cytochalasin congeners on the F/G-actin ratio of SKOV3 and SKVLB1 human ovarian carcinomas. Abbreviations are the same as those used in Fig. 2, except for the addition of Ve (verapamil). All cytochalasins were administered at their $I_{90}$ value of $96 \mathrm{~h}$ continual exposure, and Ve was administered at $30 \mu \mathrm{M}$. The F/G-actin ratio of both SKOV3 and SKVLB1 cells was assessed $24 \mathrm{~h}$ post-administration. Bars represent standard error of the mean (SEM) for each treatment group 

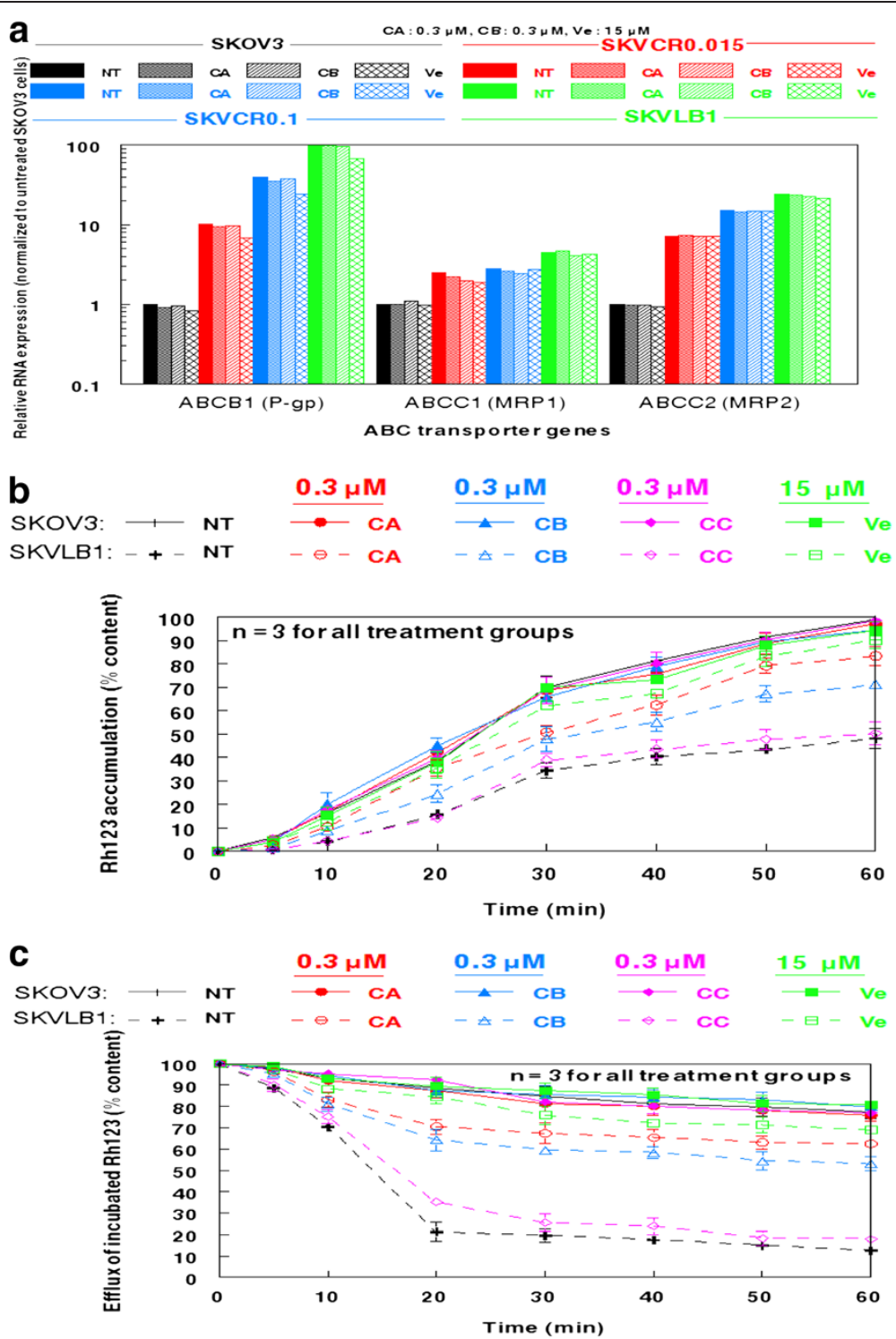

Fig. 5 Effects of cytochalasin congeners and verapamil on RNA expression of ATP binding cassette proteins and the efflux of rhodamine 123 in SK human ovarian carcinoma cell lines. a Relative RNA expression of ABCB1 (P-gp), ABCC1 (MRP1), and ABCC2 (MRP2) in SK human ovarian carcinoma cell lines prior to and after treatment with cytochlalasins as assessed by RT-PCR. Primer sequences used in the reaction are shown in Table 1. b Cells were treated with the indicated agents, and then exposed to Rh123. c Cells were incubated with Rh123, and then placed in fresh medium. The concentrations of each agent used are indicated in the individual panels. Bars represent SEM for each treatment group

rate with untreated cells reaching $12.4 \%$ content of the original Rh123 incubation and cytochalasin C treated cells reaching $17.8 \%$ content. By contrast, $0.3 \mu \mathrm{M}$ cytochalasins A or B retained much higher percentages of accumulation (62.4\% and $53.1 \%$, respectively), but were less effective than $15 \mu \mathrm{M}$ verapamil (68.9\%).

\section{Efficacy of cytochalasin B in increasing drug sensitivity}

Cytochalasin B appeared to increase the drug sensitivity of SKVLB1 cells to clinically approved antineoplastic agents known to have reduced cytotoxicity against this multidrug resistant cell line (Table 4). The $\mathrm{IC}_{90}$ values of doxorubicin against SKVLB1 cells at $13.5 \mathrm{~h}$ and at $33 \mathrm{~h}$ of exposure and for paclitaxel at $13.5 \mathrm{~h}$ dropped by 2 to 4-fold using either 0.15 or $0.60 \mu \mathrm{M}$ cytochalasin $\mathrm{B}$. This increase in sensitivity was even more pronounced with the $\mathrm{IC}_{90}$ value of paclitaxel at $33 \mathrm{~h}$, as it dropped 8-fold with $0.15 \mu \mathrm{M}$ cytochalasin $\mathrm{B}$, and 10-fold with $0.60 \mu \mathrm{M}$ cytochalasin $\mathrm{B}$. It should be noted that much higher concentrations of doxorubicin and paclitaxel were needed to obtain $\mathrm{IC}_{90}$ values against SKVLB1 than in earlier determinations because the earlier values were measured at $96 \mathrm{~h}$ of exposure, while the combination of cytochalasin B with doxorubicin or paclitaxel were measured at 13.5 and $33 \mathrm{~h}$. 
Table 4 Sensitivity to clinically approved antineoplastic agents potentiated by cytochalasin B against multidrug resistant SKVLB1 human ovarian carcinoma

\begin{tabular}{llllll}
\hline Time of exposure (Hours) & \multicolumn{1}{l}{13.5} & & 33 & \\
$\mathrm{IC}$ concentrations $(\mu \mathrm{M})$ & $\mathrm{IC}_{90}$ & $\mathrm{FS}$ & & $\mathrm{IC}_{90}$ & $\mathrm{FS}$ \\
\hline Doxorubicin & & & & 5 & - \\
$0 \mu \mathrm{M}$ Cytochalasin B & 5 & - & 2.5 & 2 \\
$0.15 \mu \mathrm{M}$ Cytochalasin B & 2.5 & 2 & & 2.3 & 4 \\
$0.60 \mu \mathrm{M}$ Cytochalasin B & 1.3 & 4 & & \\
Paclitaxel & & & & 40 & - \\
$0 \mu \mathrm{M}$ Cytochalasin B & $>40$ & - & 5 & 8 \\
$0.15 \mu \mathrm{M}$ Cytochalasin B & 20 & 2 & 5 & 10 \\
$0.60 \mu \mathrm{M}$ Cytochalasin B & 15 & 2.5 & 4 &
\end{tabular}

FS fold sensitization

\section{Assessment of drug synergy between cytochalasins and clinically approved agents}

Both cytochalasin B and DiHCB appeared to synergize with doxorubicin and paclitaxel in SKOV3 and SKVLB1 cells when combined $\mathrm{IC}_{50}$ values were plotted to form isobolograms (Fig. 6). The synergy indicated by these values was also confirmed with Chou-Talalay CI values (Table 5). In addition, DRI values for both the cytochalasins and currently approved agents were indicative of favorable dose reductions, although this would be expected from the isobolograms. Interestingly, in both measurements of synergy, it appeared that cytochalasin B and DiHCB synergized with the clinically approved agents more strongly against SKVLB1 than against drug sensitive SKOV3. This synergism was noted at other inhibitory concentrations, as indicated in Fig. 7. Although the individual values may vary, the lines of the Fa-CI plot for SKVLB1 appear to be noticeably
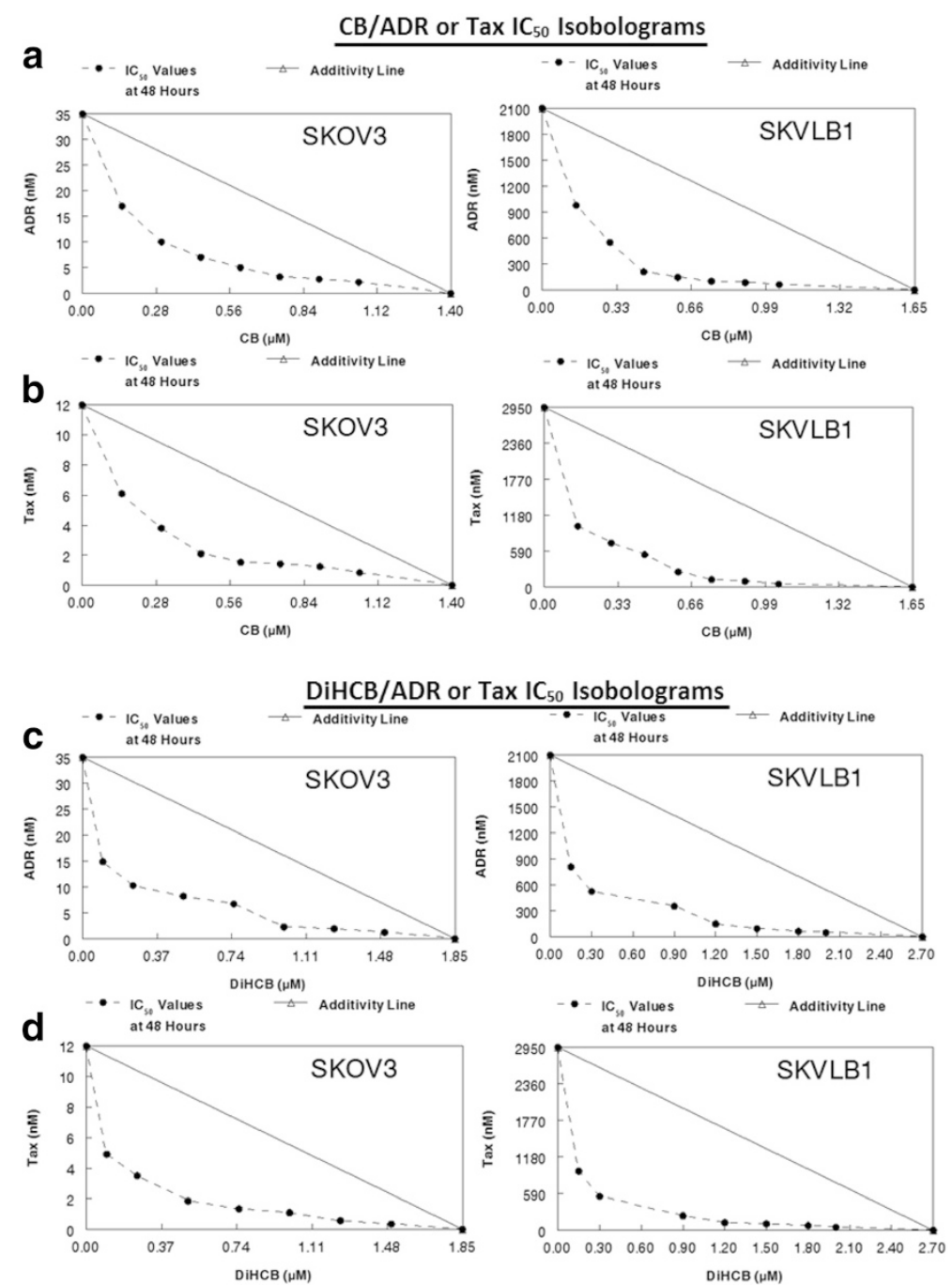

Fig. $6 I C_{50}$ isobolograms for cytochalasin B, 21, 22-dihydrocytochalasin B, doxorubicin, and paclitaxel against SKOV3 and SKVLB1 human ovarian carcinoma. a CB and ADR. b CB and Tax. c DiHCB and ADR. $\mathbf{d}$ DiHCB and Tax. IC $\mathrm{C}_{50}$ values were determined after a $48 \mathrm{~h}$ continuous exposure 
Table 5 Chou-Talalay statistics on the mean $I C_{50}$ values between cytochalasin B, 21, 22-dihydrocytochalasin B, doxorubicin, and paclitaxel against SKOV3 and SKVLB1 human ovarian carcinoma

\begin{tabular}{|c|c|c|c|c|c|}
\hline Cell line & Cytochalasin ( $\mu \mathrm{M})$ & Clinically approved agent $(\mu \mathrm{M})$ & DRI Cyt ${ }^{a}$ & DRI CAA ${ }^{b}$ & $\mathrm{Cl}$ \\
\hline \multirow[t]{4}{*}{ SKOV3 } & $0.6 \mathrm{CB}$ & $0.0067 \mathrm{ADR}$ & 3.46 & 8.20 & 0.41 \\
\hline & $0.6 \mathrm{CB}$ & $0.0023 \operatorname{Tax}$ & 3.46 & 6.99 & 0.43 \\
\hline & $0.76 \mathrm{DiHCB}$ & $0.0065 \mathrm{ADR}$ & 5.23 & 10.9 & 0.28 \\
\hline & $0.76 \mathrm{DiHCB}$ & $0.0030 \operatorname{Tax}$ & 5.23 & 12.5 & 0.27 \\
\hline \multirow[t]{4}{*}{ SKVLB1 } & $0.6 \mathrm{CB}$ & $0.30 \mathrm{ADR}$ & 4.07 & 15.7 & 0.30 \\
\hline & $0.6 \mathrm{CB}$ & 0.40 Tax & 4.07 & 19.7 & 0.29 \\
\hline & $1.12 \mathrm{DiHCB}$ & $0.29 \mathrm{ADR}$ & 5.27 & 17.5 & 0.25 \\
\hline & $1.12 \mathrm{DiHCB}$ & $0.30 \mathrm{Tax}$ & 5.27 & 22.7 & 0.23 \\
\hline
\end{tabular}

Mean values for drug concentrations, dose reduction indices, and combination indices were derived from the points used in the $\mathrm{IC}_{50}$ isobolograms, excluding single agent administrations

Cl combination index

aDose reduction index for the indicated cytochalasin

${ }^{b}$ Dose reduction index for the indicated currently approved agent

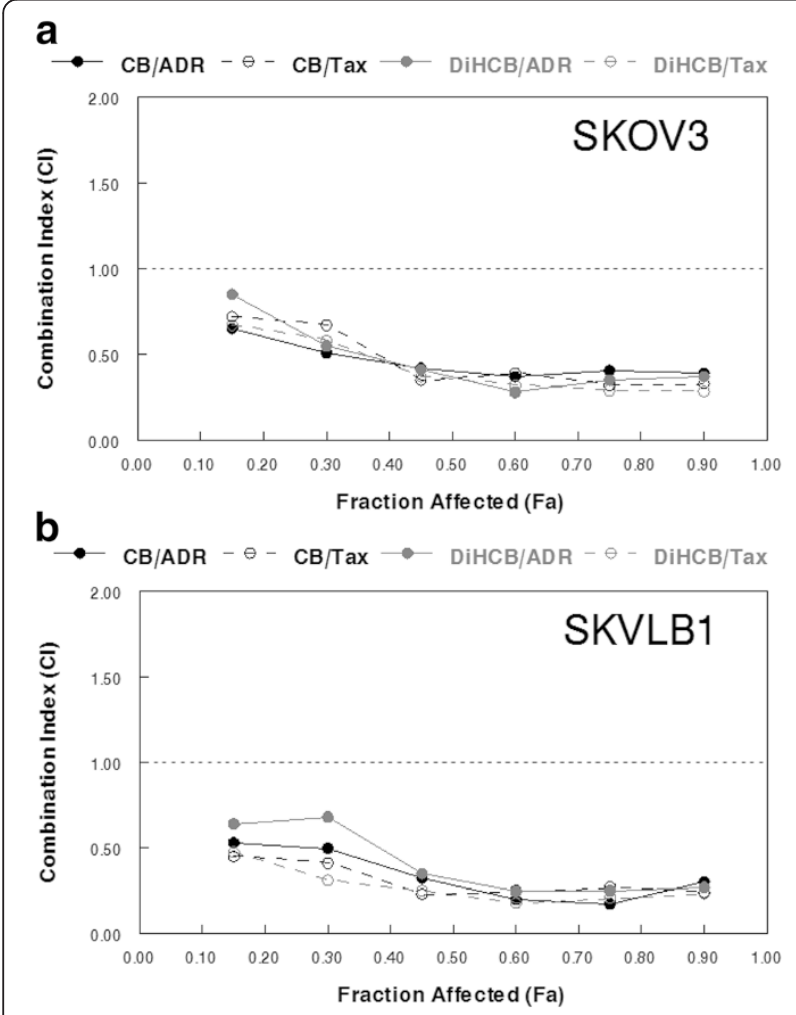

Fig. 7 Chou-Talalay method Fa-Cl plots to assess drug synergy between cytochalasin B, 21,22-dihydrocytochalasin B, doxorubicin, and paclitaxel against SKOV3 and SKVLB1 human ovarian carcinomas. a Concomitant treatments against SKOV 3 cells. $\mathbf{b}$ Concomitant treatments against SKVLB1 cells. Agents were administered continuously for $48 \mathrm{~h}$. According to the Chou-Talalay method for the assessment of drug synergy [27], $<0.1$ (very strong synergism), 0.1-0.3 (strong synergism), 0.3-0.7 (synergism), 0.7-0.85 (moderate synergism), 0.85-0.9 (slight synergism) are all values of synergism, while $0.9-1.1$ may be considered additive or potentially antagonistic, and any values greater than 1.1 are antagonistic lower than those observed for SKOV3. The potential for increased synergy may be the result of the inhibitory effect cytochalasin B and DiHCB has toward P-gp and potentially other $\mathrm{ABC}$ transporters, and will be elaborated upon in the discussion.

\section{Discussion}

With respect to SK human ovarian carcinoma cells, it appears that the nine cytochalasin congeners examined in this study fall into three groups. Against the SKOV3 cell line, cytochalasins $\mathrm{C}, \mathrm{D}, \mathrm{E}$ and $\mathrm{H}$ were less cytotoxic than are the clinically approved antineoplastic agents (doxorubicin, paclitaxel and vinblastine), with $96 \mathrm{~h}$ continuous exposure $\mathrm{IC}_{90}$ values ranging from 80 to $330 \mathrm{nM}$ (Table 1). $\mathrm{IC}_{90}$ values for the three clinically approved agents ranged from 2 to $11 \mathrm{nM}$. Cytochalasins C, D, E, and $\mathrm{H}$ as a group appeared to be subject to drug resistance against multidrug resistant SKVLB1 cells as exemplified by cytochalasin D which had a RI $=100$ against SKVLB1. While this RI was not as high as for any of the clinically approved chemotherapeutic agents in the study, it is likely that overexpression of P-gp does reduce the cytotoxicity of these congeners, presumably due to drug efflux.

The second group composed of cytochalasins B, J, DiHCB and DiHCBy-L were less cytotoxic against the parental cell line SKOV3. $\mathrm{IC}_{90}$ values ranged from 0.8 to $40 \mu \mathrm{M}$ (800 to $40,000 \mathrm{nM}$ ), and were not subject to strong resistance by SKVLB1 (RIs ranged from 1 to 4 -fold). Further, cytochalasin B, DiHCB, and DiHCBy-L were more cytotoxic against SKVCR0.015 and SKVCR0.1 than against the parental cell line with RI values below 1 (Table 1).

Finally, Cytochalasin A is unique in that it demonstrated less cytotoxicity against the parental cell line $\left(\mathrm{IC}_{90}=1 \mu \mathrm{M}\right)$ than against SKVLB1 $\left(\mathrm{IC}_{90}=0.75 \mu \mathrm{M}\right)$, indicating that it is not subject to SKVLB1 drug resistance. This suggests that cytochalasin A has unique properties with respect to inhibiting P-gp, possibly due to increased binding affinity for 
the drug efflux pump in conjunction with its electrophilic $\alpha, \beta$-unsaturated ketone moiety (Fig. 1), which could potentiate alkylation of key structures within the neoplastic cell (including P-gp). The $\alpha, \beta$-unsaturated ketone in cytochalasin A is particularly electrophilic, as it is conjugated to another ketone, making the double bond highly reactive.

It is also very likely that $\mathrm{DiHCB \gamma}-\mathrm{L}$ is not influenced by SKVLB1 drug resistance, as the $\mathrm{IC}_{90}$ values were the same against SKOV3 and SKVLB1. The potential of DiHCBY-L to inhibit P-gp may be related to its relatively low cytotoxicity. DiHCB $\gamma-\mathrm{L}$ had the highest $\mathrm{IC}_{90}$ value against SKOV3 among the nine cytochalasins $(40 \mu \mathrm{M})$. This suggests that P-gp and other $A B C$ transporters may become saturated by $40 \mu \mathrm{M}$ DiHCB $\gamma-\mathrm{L}$ in SKVLB1, and that the efflux pumps have difficulty removing such a high concentration. It is also possible that $\mathrm{DiHCB} \gamma-\mathrm{L}$ may have increased reactivity deriving from the generation of an $\alpha$-hydroxyacetamidogroup with a reactive secondary hydroxyl group at C-9 when the original lactone of DiHCB is hydrolyzed (Fig. 1), or it may have unique binding capability with $A B C$ transporters. Along with cytochalasin A, DiHCBY-L may have properties with respect to the drug efflux pump system that would make these two congeners of special interest in preclinical evaluations.

With respect to the intermediately resistant cell line SKVCR0.015, all of the cytochalasins tested (cytochalasins $\mathrm{A}, \mathrm{B}, \mathrm{C}, \mathrm{D}, \mathrm{DiHCB}$, and $\mathrm{DiHCB}$-L) were equally or more cytotoxic than against SKOV3. All of these cytochalasins except for cytochalasin $\mathrm{C}$ also showed equal or enhanced sensitivity rather than resistance when tested against the intermediately resistant cell line SKVCR0.1 (cytochalasins $\mathrm{E}, \mathrm{H}$, and $\mathrm{J}$ were not tested against the intermediately resistant cell lines). These data suggest that multidrug resistant pumps can be completely overridden by cytochalasins unless there is very high expression of the pumps as in the highly resistant SKVLB1 cell line.

As shown with cytochalasins B, C, D and DiHCB, verapamil was able to increase the cytotoxicity of congeners affected by P-gp overexpression in SKVLB1 cells (Table 3). This increase in cytotoxicity was substantial with the more cytotoxic cytochalasins C and D (32- and 64-fold increase in sensitivity against SKVLB1), which had much higher RIs against SKVLB1 than other congeners. Nevertheless, even less cytotoxic congeners such as cytochalasin B and DiHCB had lower $\mathrm{IC}_{90}$ values against all drug resistant cell lines when combined with $30 \mu \mathrm{M}$ verapamil (Fig. 3a). Further, growth inhibition of SKVCR0.015 cells at varying concentrations of cytochalasin $\mathrm{B}$ was more pronounced after the addition of $30 \mu \mathrm{M}$ verapamil (Fig. 3e), validating previous observations that calcium ion channel blockers can be used to overcome P-gp mediated drug resistance [28-30]. Interestingly, it appeared that verapamil had some propensity to modulate P-gp expression (Fig. 5a), suggesting that it may perturb P-gp function through mechanisms other than direct inhibition of the efflux protein. In addition, verapamil had a slight, but noticeable influence on F/G-actin ratios in both SKOV3 and SKVLB1 (Fig. 4), an observation in accord with prior studies that have noted $\mathrm{Ca}^{2+}$ oscillations trigger the depolymerization of microfilaments [31-33]. Together, these data indicate that microfilaments may be a feasible target for inhibiting drug efflux (although the influence verapamil has on microfilaments may merely be an off target effect). This is in accord with Table 3 and Figs. 3 and 4, as concomitant administration of cytochalasin $B$ and verapamil potentiates the cytotoxicity and reduction of F-actin significantly more than cytochalasin B administered as a single agent.

Although verapamil appears to increase the cytotoxicity of most cytochalasins examined in the present study, it is evident that at least some of these congeners have $A B C$ transporter inhibitory activity. As demonstrated in Figs. 5b and c, cytochalasins $\mathrm{A}$ and $\mathrm{B}$, but not cytochalasin $\mathrm{C}$, are able to inhibit the ability of SKVLB1 cells to efflux Rh123. These data parallel the 4 day $\mathrm{IC}_{90}$ values attained for these agents against SKVLB1, suggesting that the marked cytotoxicity cytochalasin A and potentially other cytochalasins had against the multidrug resistant cell line was at least partially attributed to inhibition of drug efflux. This appears feasible as congeners more cytotoxic against the parental SKOV3 cell line potentiated lower F-actin levels against SKOV3 than they did against SKVLB1, a cell line that has an inherently lower F/G-actin ratio (Fig. 4). By contrast, cytochalasin A elicited a significantly lower F/G-actin ratio against SKVLB1, suggesting that the compound was not being pumped out at as high of a rate as the more potent F-actin inhibitors. In addition, this figure highlights the potential utility of microfilament-disrupting agents, as multidrug resistant SKVLB1 appears to have a lower ratio of F/ G-actin than drug sensitive SKOV3, and normal cells often have higher levels of F-actin than their neoplastic counterparts $[34,35]$. Disruption of the actin cytoskeleton is known to induce apoptosis in malignant cells $[1,35]$, and exploiting their already perturbed microfilament network may provide a novel antineoplastic mechanism that warrants clinical investigation.

Besides the potential of using cytochalasin congeners against certain drug resistant cancers, there exists the possibility of concomitant chemotherapy with clinically approved agents to increase their cytotoxicity. As demonstrated in Table 4, sufficient concentrations of cytochalasin B can increase the drug sensitivity of SKVLB1 to doxorubicin and paclitaxel. A formal assessment of drug synergy through isobolographic analysis (Fig. 6) and Chou-Talalay statistics (Fig. 7 and Table 5) further confirmed the potential utility of facilitating the cytotoxicity of currently approved agents with cytochalasins, as both cytochalasin B and DiHCB demonstrated notable 
synergism with doxorubicin and paclitaxel. The extent of the drug synergy between cytochalasin B, DiHCB, and doxorubicin against SKVLB1 was comparable to the activity we previously observed in P388/ADR leukemia [14], another multidrug resistant cell line. These observations, along with previous studies that noted drug synergy between cytochalasin B and cytarabine [36] as well as vincristine [37], provide compelling evidence that cytochalasin $\mathrm{B}$ and its reduced congener have clinically applicable synergistic potential.

These data are in alignment with the antineoplastic mechanisms of microfilament-disrupting agents such as cytochalasin B. Due to cytokinesis inhibition potentiated by this class of agents, neoplastic cells become enlarged and multinucleated; ideal targets for microtubule-directed (paclitaxel) and for nucleic acid-directed (doxorubicin) agents $[1,38]$. Further, the concomitant perturbation of the cell cycle via microtubule-targeting $\mathrm{G}_{2} / \mathrm{M}$ arrest and microfilament-targeting cytokinesis inhibition leaves two unique mechanisms that neoplastic cells would have to circumvent in order to continuously proliferate. Indeed, we have previously observed that concomitant administration of cytochalasin B and vincristine substantially precludes the clonogenic potential of U937 human monocytic leukemia, thereby potently inhibiting its propensity to proliferate [39]. Therefore, cytochalasins have unique microfilament-directed mechanisms that may substantiate potent drug synergy with agents that target microtubules or nucleic acids.

Interestingly, we have demonstrated that pulsed lowfrequency ultrasound in the 20 to $40 \mathrm{kHz}$ range is able to induce preferential destruction of neoplastic cells enlarged by treatment with cytoskeletal-directed agents $[39,40]$. The ability of cytochalasins to affect multidrug resistant neoplastic cells presents the possibility of cell enlargement and multinucleation in these cells that has been observed in all other neoplastic cell lines tested. Consequently, cytochalasins may sensitize multidrug resistant cells to sonodynamic therapy with low frequency ultrasound, paralleling the effects obtained to this point with leukemic cell targets.

\section{Conclusion}

Currently, ovarian carcinoma presents significant clinical issues, as the 5 year survival rate for all stages and types is $44 \%$, while stage IV invasive ovarian carcinoma has a 5 year survival rate of $17 \%$ [41]. Further, only $15 \%$ of all ovarian tumors are found at stage I [41], indicating that clinicians often have to treat aggressive malignancies. These data suggest that novel antineoplastic agents need to be devised for the treatment of ovarian carcinoma. Cytochalasins offer novel mechanisms for exploitation in cancer therapy that may improve the efficacy of treatments against cancers refractory to standard chemotherapeutic protocols. In vivo efficacy of cytochalasins in preclinical models of drug resistant ovarian carcinoma has yet to be determined. Such preclinical investigation is warranted based on the results of this study.

\section{Competing interests}

The authors declare that they have no competing interests.

\section{Authors' contributions}

MT performed some of the experimental work, developed the figures and tables, and wrote the manuscript. TDC performed experimental work that contributed to the manuscript. CA performed experimental work that contributed to the manuscript. TPF performed a significant amount of the experimental work, and helped revise the manuscript. All authors read and approved the final manuscript.

\section{Acknowledgments}

The authors would like to thank Dr. Victor Ling of the University of British Columbia for providing the cell lines used in this study. The authors would also like to extend their sincerest gratitude to two anonymous reviewers who improved the quality of the article.

Received: 16 February 2015 Accepted: 21 August 2015

Published online: 10 September 2015

\section{References}

1. Trendowski M. Exploiting the cytoskeletal filaments of neoplastic cells to potentiate a novel therapeutic approach. Biochim Biophys Acta Reviews on Cancer. 1846;2014:599-616.

2. Van Goietsenoven G, Mathieu V, Andolfi A, Cimmino A, Lefranc F, Kiss R, et al. In vitro growth inhibitory effects of cytochalasins and derivatives in cancer cells. Planta Med. 2011;77:711-7.

3. Kelly F, Sambrook J. Differential effect of cytochalasin B on normal and transformed mouse cells. Nat New Biol. 1973;242:217-9.

4. Medina D, Oborn CJ, Asch BB. Distinction between preneopastic and neoplastic mammary cell populations in vitro by cytochalasin B-induced multinucleation. Cancer Res. 1980;40:329-33.

5. Somers KD, Murphey MM. Cytochalasin B-induced multinucleation of human tumor and normal cell cultures. Cell Biol Int Rep. 1980;4:487-95.

6. Steiner MR, Altenburg B, Richards CS, Dudley JP, Medina D, Butel JS. Differential response of cultured mouse mammary cells of varying tumorigenicity to cytochalasin B. Cancer Res. 1978;38:2719-21.

7. Somers KD, Murphey MM. Multinucleation in response to cytochalasin B: a common feature in several human tumor cell lines. Cancer Res. 1982:42:2575-8.

8. Huang FY, Li YN, Mei WL, Dai HF, Zhou P, Tan GH. Cytochalasin D, a tropical fungal metabolite, inhibits CT26 tumor growth and angiogenesis. Asian Pac J Trop Med. 2012;5:169-74.

9. Małecki JM, Bentke A, Ostrowska B, Laidler P. Cytochalasin D, LY294002 and olomoucine synergize in promoting death of melanoma cells through activation of caspase-3 and apoptosis. Melanoma Res. 2010;20:52-8.

10. Huang FY, Mei WL, Li YN, Tan GH, Dai HF, Guo JL, et al. The antitumour activities induced by pegylated liposomal cytochalasin $\mathrm{D}$ in murine models. Eur J Cancer. 2012;48:2260-9.

11. Rao JY, Hurst RE, Bales WD, Jones PL, Bass RA, Archer LT, et al. Cellular F-actin levels as a marker for cellular transformation: relationship to cell division and differentiation. Cancer Res. 1990;50:2215-20.

12. Ben-Ze'ev A. The cytoskeleton in cancer cells. Biochim Biophys Acta. 1985;780:197-212.

13. Bousquet PF, Paulsen LA, Fondy C, Lipski KM, Loucy KJ, Fondy TP. Effects of cytochalasin $B$ in culture and in vivo on murine Madison 109 lung carcinoma and on B16 melanoma. Cancer Res. 1990;50:1431-9.

14. Trendowski M, Mitchell JM, Corsette CM, Acquafondata C, Fondy TP. Chemotherapy with cytochalasin congeners in vitro and in vivo against murine models. Invest New Drugs. 2015;33(2):290-9.

15. Smith CD, Carmeli S, Moore RE, Patterson GM. Scytophycins, novel microfilament-depolymerizing agents which circumvent P-glycoprotein-mediated multidrug resistance. Cancer Res. 1993;53:1343-7.

16. Shaw TJ, Senterman MK, Dawson K, Crane CA, Vanderhyden BC. Characterization of intraperitoneal, orthotopic, and metastatic xenograft models of human ovarian cancer. Mol Ther. 2004;10:1032-42. 
17. Anglesio MS, Wiegand KC, Melnyk N, Chow C, Salamanca C, Prentice LM, et al. Type-specific cell line models for type-specific ovarian cancer research. PLoS One. 2013;8:e72162.

18. Bradley G, Naik M, Ling V. P-glycoprotein expression in multidrug-resistant human ovarian carcinoma cell lines. Cancer Res. 1989;49:2790-6.

19. Speicher LA, Barone LR, Chapman AE, Hudes GR, Laing N, Smith CD, et al. P-glycoprotein binding and modulation of the multidrug-resistant phenotype by estramustine. J Natl Cancer Inst. 1994;86:688-94.

20. Chabner BA, Longo DL. Cancer chemotherapy and biotherapy: principles and practice, 5th Edition. Philadelphia, PA: Lipincott Williams \& Wilkins; 2011

21. Yusa K, Tsuruo T. Reversal mechanism of multidrug resistance by verapamil: direct binding of verapamil to P-glycoprotein on specific sites and transport of verapamil outward across the plasma membrane of K562/ADM cells. Cancer Res. 1989;49:5002-6.

22. Futscher BW, Foley NE, Gleason-Guzman MC, Meltzer PS, Sullivan DM, Dalton WS. Verapamil suppresses the emergence of

P-glycoprotein-mediated multi-drug resistance. Int J Cancer. 1996;66:520-5.

23. Fojo AT, Shen DW, Mickley LA, Pastan I, Gottesman MM. Intrinsic drug resistance in human kidney cancer is associated with expression of a human multidrug-resistance gene. J Clin Oncol. 1987;5:1922-7.

24. Mickisch GH, Merlino GT, Galski H, Gottesman MM, Pastan I. Transgenic mice that express the human multidrug-resistance gene in bone marrow enable a rapid identification of agents that reverse drug resistance. Proc Natl Acad Sci USA. 1991;88:547-51.

25. Lipski KM, McQuiggan JD, Loucy KJ, Fondy TP. Cytochalasin B: preparation, analysis in tissue extracts, and pharmacokinetics after intraperitoneal bolus administration in mice. Anal Biochem. 1987;161:332-40.

26. Trendowski M, Wong V, Wellington K, Hatfield S, Fondy TP. Tolerated doses in zebrafish of cytochalasins and jasplakinolide for comparison with tolerated doses in mice in the evaluation of pre-clinical activity of microfilament-directed agents in tumor model systems in vivo. In Vivo. 2014;28(6):1021-31.

27. Chou TC. Theoretical basis, experimental design, and computerized simulation of synergism and antagonism in drug combination studies. Pharmacol Rev. 2006;58(3):621-81.

28. Presant CA, Kennedy PS, Wiseman C, Gala K, Bouzaglou A, Wyres M, et al. Verapamil reversal of clinical doxorubicin resistance in human cancer. A Wilshire Oncology Medical Group pilot phase I-II study. Am J Clin Oncol. 1986;9:355-7.

29. Miller TP, Grogan TM, Dalton WS, Spier CM, Scheper RJ, Salmon SE. P-glycoprotein expression in malignant lymphoma and reversal of clinical drug resistance with chemotherapy plus high-dose verapamil. J Clin Oncol. 1991;9:17-24.

30. Taylor CW, Dalton WS, Mosley K, Dorr RT, Salmon SE. Combination chemotherapy with cyclophosphamide, vincristine, adriamycin, and dexamethasone (CVAD) plus oral quinine and verapamil in patients with advanced breast cancer. Breast Cancer Res Treat. 1997:42:7-14.

31. Rosenmund C, Westbrook GL. Calcium-induced actin depolymerization reduces NMDA channel activity. Neuron. 1993;10(5):805-14.

32. Dartsch PC, Ritter M, Häussinger D, Lang F. Cytoskeletal reorganization in $\mathrm{NIH} 3 \mathrm{~T} 3$ fibroblasts expressing the ras oncogene. Eur J Cell Biol. 1994;63(2):316-25.

33. Lang F, Busch GL, Ritter M, Völkl H, Waldegger S, Gulbins E, et al. Functional significance of cell volume regulatory mechanisms. Physiol Rev. 1998;78(1):247-306.

34. Stournaras C, Stiakaki E, Koukouritaki SB, Theodoropoulos PA, Kalmanti M, Fostinis $Y$, et al. Altered actin polymerization dynamics in various malignant cell types: evidence for differential sensitivity to cytochalasin B. Biochem Pharmacol. 1996;52(9):1339-46.

35. Desouza M, Gunning PW, Stehn JR. The actin cytoskeleton as a sensor and mediator of apoptosis. Bioarchitecture. 2012;2(3):75-87.

36. O'Neill FJ. Selective destruction of cultured tumor cells with uncontrolled nuclear division by cytochalasin B and cytosine arabinoside. Cancer Res. 1975;35:3111-5.

37. Kolber MA, Hill P. Vincristine potentiates cytochalasin B-induced DNA fragmentation in vitro. Cancer Chemother Pharmacol. 1992;30:286-90.

38. Trendowski M. Using cytochalasins to improve current chemotherapeutic approaches. Anticancer Agents Med Chem. 2015;15(3):327-35.
39. Trendowski M, Wong V, Zoino JN, Christen TD, Gadeberg L, Sansky M, et al. Preferential enlargement of leukemia cells using cytoskeletal-directed agents and cell cycle growth control parameters to induce sensitivity to low frequency ultrasound. Cancer Lett. 2015;360(2):160-70.

40. Trendowski M, Yu G, Wong V, Acquafondata C, Christen T, Fondy TP. The real deal: using cytochalasin B in sonodynamic therapy to preferentially damage leukemia cells. Anticancer Res. 2014;34:2195-202.

41. Siegel RL, Miller KD, Jemal A. Cancer statistics, 2015. CA Cancer J Clin. 2015;65(1):5-29.

\section{Submit your next manuscript to BioMed Central and take full advantage of:}

- Convenient online submission

- Thorough peer review

- No space constraints or color figure charges

- Immediate publication on acceptance

- Inclusion in PubMed, CAS, Scopus and Google Scholar

- Research which is freely available for redistribution 